American Journal of Applied Sciences 6 (7): 1429-1435, 2009

ISSN 1546-9239

(C) 2009 Science Publications

\title{
Hydraulic Characteristics and Pore Water Flow Rule in Constant Rate of Strain Consolidation
}

\author{
${ }^{1}$ H. Ahmadi, ${ }^{1}$ A.H. Hoorfar, ${ }^{1}$ H. Rahimi and ${ }^{2}$ A. Soroush \\ ${ }^{1}$ Department of Water Engineering, Faculty of Soil and Water, University of Tehran, Iran \\ ${ }^{2}$ Department of Civil and Environmental Engineering, \\ Technical University of Amir Kabir, Iran
}

\begin{abstract}
Problem statement: At present study Constant Rate of Strain (CRS) consolidation under Non-Darcy condition was investigated. Approach: In this study a governing conditions on pore water flow were investigated using proposed equation and experimental tests. CRS experiments under different rates of strain were conducted on different soil samples. Results: Results of these experiments and there comparison with proposed equation showed that flow of pore water flow in the most part of each test was Non-Darcy and changed to Darcy condition in the final almost one forth of tests. Conclusion: According to the results the threshold where Non-Darcy flow changes to Darcy was dependent on variations of relative pore water pressure versus total strain and it can be determined based on variations in inclination of relative pore water pressure-total stress curve.
\end{abstract}

Key words: Consolidation, constant strain, non-darcy flow, pore pressure

\section{INTRODUCTION}

The first theory of CRS consolidation was presented by Crawford and Hamilton to cover disadvantages and limitations of incremental consolidation test. Nevertheless, they applied very slow strain rates as $0.005-.015 \% \mathrm{~min}^{-1}$, excess pore presser was created and of course they didn't record ${ }^{[5]}$. One decade after the first theory, Smith and Whals and also Wissa et al ${ }^{[15,16]}$ more developed theory and also they have proposed practical criteria for conducting CRS test.

Lee et $a l .{ }^{[9]}$ based on moving boundary and large strain theory defined a nondimentional parameter to choice proper strain rate. He also presented two equations to determine coefficient of consolidation. Almeida et al. ${ }^{[1]}$ conducted some CRS consolidation tests on Brazil clays based on nondimetional parameter which was presented by Lee et al.$^{[9]}$ but they didn't get correct results and criticized Lee methods. Actually, CRS consolidation tests several times rejected by some researchers ${ }^{[13,14]}$. Selection of proper strain rate is an open question in CRS consolidation ${ }^{[3]}$. Researchers employ ratio of pore water presser at bottom of sample to applied total stress as a standard criterion. In literatures rigorous different exist between acceptable range of this criterion. For example based on Wissa et al. ${ }^{[15]}$ works it should be less than 0.05, ASTM (D4186-86) propose it between 0.03 until 0.3. However, Sheahan and Watters ${ }^{[13]}$ got correct test results while ratio of pore presser at the bottom of sample to applied stress was more than $71 \%{ }^{[13]}$. Authors didn't find reason of mentioned difference ${ }^{[15]}$. It may be related to the main assumptions that are included in theory of CRS test. During progressive of consolidation settlement rate of excess pore water dissipation has a main rule which is depending on hydraulic of pore water flow $^{[3]}$ and all equations have derived based on Darcy flow rule. Similar to incremental consolidation theory flow rule in CRS test was assumed as Darcy. At present study authors included Non-Darcy flow rule in CRS consolidation theory and the flow rule was investigated. This is one of the first studies about validity of NonDarcian flow in CRS consolidation.

\section{MATERIALS AND METHODS}

Mathematical model: The flow rule based on NonDarcy conditions is:

$$
\mathrm{v}_{\mathrm{z}}=-\mathrm{ki}^{\mathrm{n}}=-\frac{\mathrm{k}}{\gamma_{\mathrm{w}}{ }^{\mathrm{n}}}\left(\frac{\partial \mathrm{u}}{\partial \mathrm{z}}\right)^{\mathrm{n}}
$$

Where:

$\mathrm{k}=$ Permeability of soil

$\mathrm{i}=$ Hydraulic gradient

$\mathrm{n}=\mathrm{A}$ constant parameter related to nonlinearity of flow which has been proposed as 1.55 by Hansbo ${ }^{[5-7]}$

Corresponding Author: H. Ahmadi, Department of Water Engineering, Faculty of Soil and Water, University of Tehran, Iran 
Am. J. Applied Sci., 6 (7): 1429-1435, 2009

Table 1: Charactrestics of studied soils

\begin{tabular}{lllllllllll}
\hline Sampling & Location & Soil class & LL $(\%)$ & PL $(\%)$ & Clay $(\%)$ & Silt (\%) & Sand $(\%)$ & Gs & D (mm) & H (mm) \\
\hline A & Karaj & CL & 41.5 & 19.0 & 37 & 59 & 4 & 2.71 & 100 & 20 \\
B & Moghan & CL & 35.5 & 16.5 & 30 & 54 & 6 & 2.67 & 100 & 20 \\
C & Lilla EDET & CH & 75.0 & 15.0 & 93 & 7 & 0 & 2.64 & 50 & 20 \\
D & Gra LERA & CH & 82.0 & 16.0 & 95 & 5 & 0 & 2.68 & 50 & 20 \\
\hline
\end{tabular}

By including Eq. 1 in continuity equation of water flow in a soil element the main consolidation equation for Non-Darcy conditions will be:

$\frac{\mathrm{nk}}{\gamma_{\mathrm{w}}{ }^{\mathrm{n}}}\left(\frac{\partial \mathrm{u}}{\partial \mathrm{z}}\right)^{\mathrm{n}-1}\left(\frac{\partial^{2} \mathrm{u}}{\partial \mathrm{z}^{2}}\right)=\frac{1}{1+\mathrm{e}} \frac{\partial \mathrm{e}}{\partial \mathrm{t}}$

If $\dot{\varepsilon}$ present the strain rate of the test, the vertical displacement of the soil sample $\delta$ and volume change $\Delta \mathrm{V}$ are:

$\delta=\dot{\varepsilon} t H$

$\Delta \mathrm{V}=\dot{\varepsilon} \mathrm{tHA}$

Where:

$\mathrm{A}=$ The Area of the sample

$\mathrm{H}=$ The initial height of the sample

The volume change of the soil is equal to the change in the void volume. Thus, the void ratio during CRS loading is given by:

$\mathrm{e}=\mathrm{e}_{0}-\frac{\dot{\varepsilon} \mathrm{tHA}}{\mathrm{V}_{\mathrm{s}}}$

Where:

$\mathrm{e}_{0}=$ The initial void ratio

$\mathrm{V}_{\mathrm{s}}=$ The volume of soil particles

Based on Eq. 5 the rate of change of void ratio can be given by:

$$
\frac{\mathrm{de}}{\mathrm{dt}}=-\frac{\dot{\varepsilon} \mathrm{HA}}{\mathrm{V}_{\mathrm{s}}}=-\mathrm{C}
$$

Substituting Eq. 5 and 5 into Eq. 2 yields:

$$
\frac{\mathrm{nk}}{\gamma_{\mathrm{w}}{ }^{\mathrm{n}}}\left(\frac{\partial \mathrm{u}}{\partial \mathrm{z}}\right)^{\mathrm{n}-1}\left(\frac{\partial^{2} \mathrm{u}}{\partial \mathrm{z}^{2}}\right)=\frac{-\mathrm{C}}{1+\mathrm{e}_{0}-\mathrm{Ct}}
$$

Regarding to CRS consolidation tests, the boundary conditions for Eq. 7 are expressed as:

$\mathrm{u}(0, \mathrm{t})=0$

$$
\frac{\partial \mathrm{u}}{\partial \mathrm{z}}(\mathrm{H}, \mathrm{t})=0
$$

By two times integration respect in $\mathrm{Z}$ and applying 8 and 9 boundary conditions the Eq. 9 will be:

$$
u(z, t)=\gamma_{w}\left(\frac{n}{n+1}\right)\left(\frac{C}{k}\right)^{\frac{1}{n}} \frac{H^{\frac{n+1}{n}}-(H-z)^{\frac{n+1}{n}}}{\left(1+e_{0}-C t\right)^{\frac{1}{n}}}
$$

By substituting $\mathrm{z}$ as $\mathrm{H}$ in Eq. 10, pore pressure at the bottom of sample will be:

$$
\mathrm{u}_{\mathrm{b}}=\mathrm{u}(\mathrm{H}, \mathrm{t})=\gamma_{\mathrm{w}}\left(\frac{\mathrm{n}}{\mathrm{n}+1}\right)\left(\frac{\mathrm{C}}{\mathrm{k}}\right)^{\frac{1}{\mathrm{n}}} \frac{\mathrm{H}^{\frac{\mathrm{n}}{\mathrm{n}+1}}}{\left(1+\mathrm{e}_{0}-\mathrm{Ct}\right)^{\frac{1}{\mathrm{n}}}}
$$

In the state of $n=1$ all equations change to Darcy condition, However in this research for Non-Darcy condition $\mathrm{n}$ value was assumed 1.55 based on Hansbo $\operatorname{research}^{[6-8]}$.

Experimental works: The experimental works were conducted with two different CRS apparatus on reconstituted and undisturbed soil samples in soil mechanics labs of Tehran University (Iran) and Chalmers Technical University (Sweden). Figure 1 and 2 show scheme of apparatuses were used in this study. The soil samples which were used in Iran selected from Moghan and Karaj regions of country and prepared by slurry technique. Firstly enough mass of soil sieved by sieve No. 40 and added to water and mixed until homogeneous slurry achieved. At last slurry filled in big consolidometer $(65 \mathrm{~cm}$ diameter and $300 \mathrm{~cm}$ height) and left it for self consolidation. Finally the main specimens were gotten for tests. Two another undisturbed clays from North West part of Goteborg city as Lila EDET and Gra LERA regions selected for testing. Table 1 shows some properties of studied clays. To studding effect of strain rate, 4 different rates were applied on similar samples. Because of comparatively high permeability of samples which selected from Iran, relatively fast rates of strain were applied. Table 2 shows the conducted tests and relevant strains. The one way drainage is used in both devices. The pore pressure at the bottom of samples (impermeable side of specimens) was recorded. In 
order to record the deformation and applied stress LVDT and load cell were used respectively. The evolution of test was monitored by computer during the test thoroughly.

Table 2: Studied specimens and applied strain rates

\begin{tabular}{lllllc}
\hline Sample & $\begin{array}{l}\text { Initial } \\
\text { void } \\
\text { ratio }\end{array}$ & $\begin{array}{l}\text { Water } \\
\text { content } \\
(\%)\end{array}$ & $\begin{array}{l}\text { Initial } \\
\text { height } \\
(\mathrm{mm})\end{array}$ & $\begin{array}{l}\text { Strain } \\
\text { rate }(\%) \\
\mathrm{min}^{-1}\end{array}$ & $\begin{array}{l}\text { Maximum } \\
\text { pore pressure } \\
\text { u }(\mathrm{kPa})\end{array}$ \\
\hline 1A1 & 1.78 & 74.20 & 19.93 & 0.025 & 7.24 \\
1A2 & 1.76 & 72.30 & 19.95 & & 8.50 \\
1A3 & 1.75 & 75.62 & 19.91 & & 7.10 \\
2A1 & 1.80 & 70.20 & 19.82 & 0.050 & 90.00 \\
2A2 & 1.79 & 65.40 & 19.85 & & 105.00 \\
2A3 & 1.77 & 67.40 & 19.87 & & 101.00 \\
3A1 & 1.76 & 68.10 & 19.57 & 0.250 & 245.00 \\
3A2 & 1.73 & 62.50 & 19.95 & & 237.00 \\
3A3 & 1.75 & 64.10 & 19.68 & & 382.00 \\
4A1 & 1.77 & 68.10 & 19.80 & 0.375 & 623.00 \\
4A2 & 1.69 & 71.40 & 19.38 & & 571.00 \\
4A3 & 1.73 & 69.30 & 19.67 & & 592.00 \\
1B & 1.83 & 67.40 & 20.00 & 0.025 & 9.40 \\
2B & 1.81 & 66.20 & 20.00 & 0.050 & 132.60 \\
3B & 1.87 & 70.10 & 20.00 & 0.250 & 253.00 \\
4B & 1.80 & 68.40 & 20.00 & 0.375 & 526.00 \\
1C & 2.40 & 89.00 & 20.00 & 0.001 & 2.00 \\
2C & 2.40 & 88.00 & 20.00 & 0.006 & 14.00 \\
3C & 2.41 & 89.00 & 20.00 & 0.012 & 22.00 \\
4C & 2.50 & 84.00 & 20.00 & 0.024 & 50.60 \\
1D & 0.90 & 33.00 & 20.00 & 0.001 & 1.70 \\
2D & 0.95 & 35.00 & 20.00 & 0.006 & 9.60 \\
3D & 0.93 & 32.96 & 20.00 & 0.012 & 22.00 \\
4D & 0.92 & 32.96 & 20.00 & 0.024 & 35.50 \\
\hline & & & & &
\end{tabular}

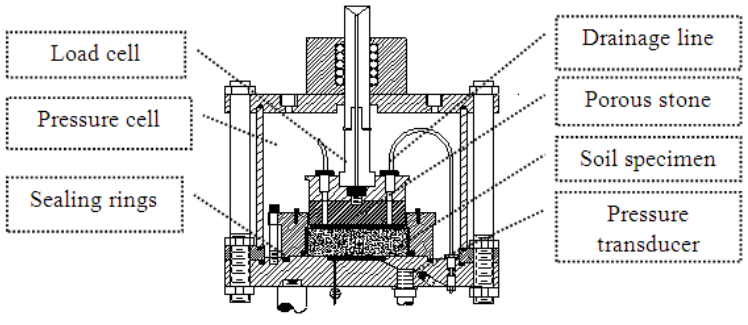

Fig. 1: Scheme of CRS consolidometer which was used in University of Tehran

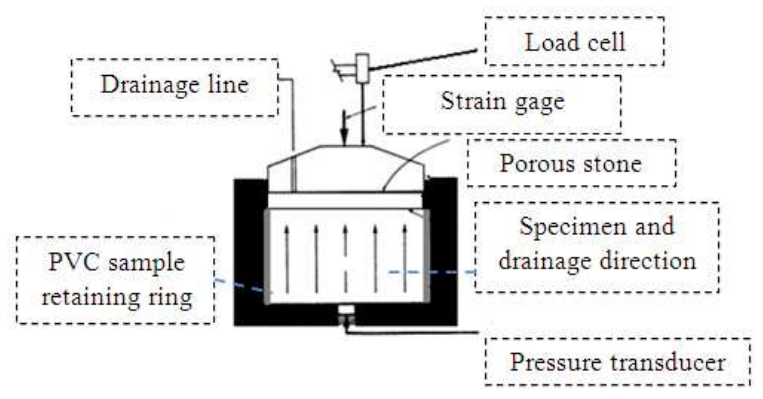

Fig. 2: Scheme of CRS consolidometer which was used in University of Tehran

\section{RESULTS}

As stated above, pore pressure at the bottom of sample was measured. Compression of Eq. 11 and recorded bottom pore pressure results showed that there is a good agreement between Non-Darcy equations (Eq. 11, $\mathrm{n}=1.55$ ) with test results (Fig. 3a). Nevertheless, in some cases these correlations is just in first half of test, but in the second one results of Eq. 11 This is may be due to the second half of experiment that the flow rule differs from Non-Darcy and changes to Darcy.

Drainage behavior of studied samples: The differences in ratio of pore pressure to total stress versus applied stress are using as a criterion for controlling CRS consolidation test ${ }^{[2,3,10]}$ An investigation of behavior of relative pore pressure versus total stress showed that the trend of curves can be revealed in two different forms (Fig. 4 and 5). In the slower test which is shown in Fig. 4, as an overall trend,

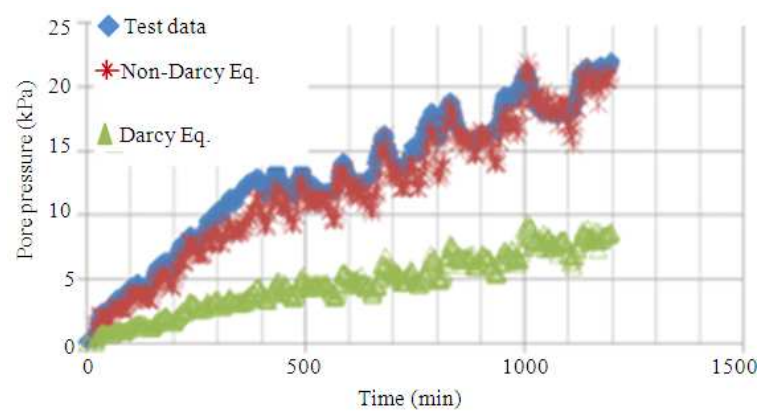

(a)

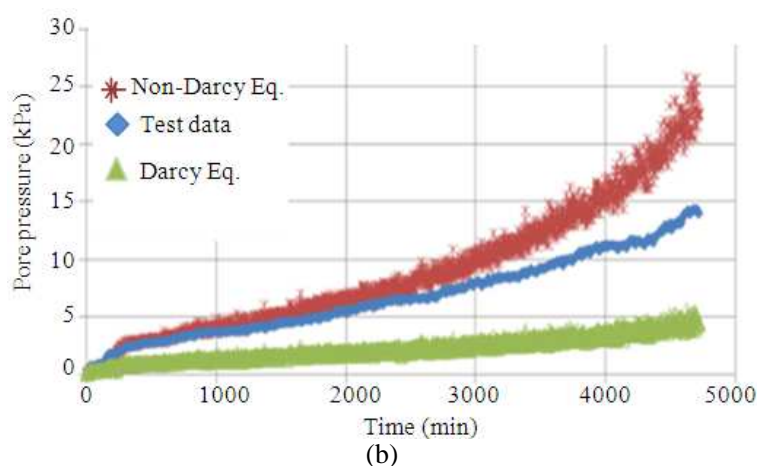

Fig. 3: Developing of pore pressure at the base of specimens and comparison with Eq. 11, in Darcy $(\mathrm{n}=1)$ and Non-Darcy $(\mathrm{n}=1.55)$ and experimental results are separating from each other in which results of equation 11 show higher values; (a): Sample 3D; (b): Sample 2C 
Am. J. Applied Sci., 6 (7): 1429-1435, 2009

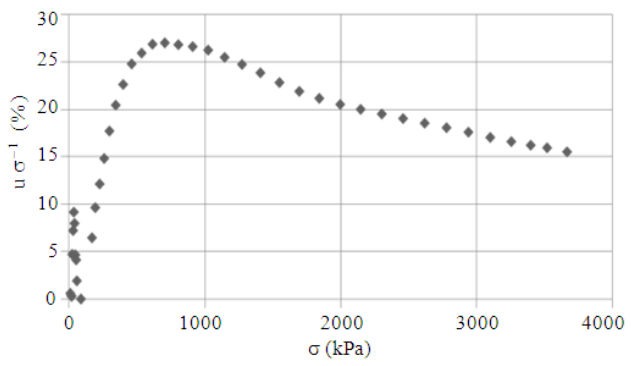

Fig. 4: Variation of pore pressure versus applied stress (Sample 4B)

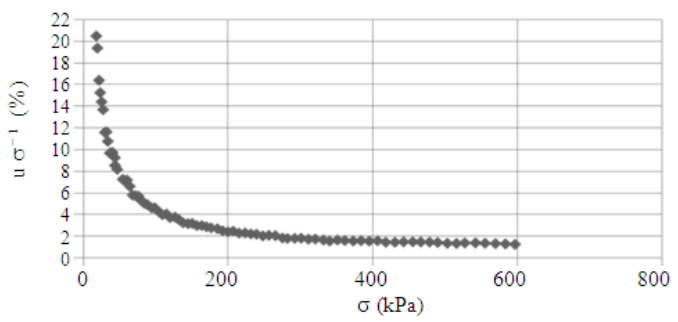

Fig. 5: Variation of pore pressure versus applied stress (Sample 1B)

it is clear that the relative pore pressure decreased fairly rapidly at first part of the test and then almost remained constant with very smooth reduction. In the rapid tests, all mentioned trend of slower tests is happening in the beginning parts of the test. Exactly, in the rapid test the curve can be divided in three parts as first, mid and last parts. For example in Fig. 5, as a rapid test, just after starting of the test relative pore pressure dropped down sharply until a minimum value (First part) before increasing steeply to a maximum value (Mid part).

After the maximum value the trend of curve changed again and inclined slowly (Last part).The length of each mentioned parts depend on the applied strain rate. Exactly, in the slower tests we have just the first and last parts of rapid tests

The changing trend of relative pore pressure-total stress can be explained as fallow. At the starting of any CRS test total stress is almost zero but maybe there is residual pore pressure on transducer it cause the ratio of pore pressure to total stress being a big value. Stress applying is caused to excess pore pressure. At the first parts of test excess pore pressure at the bottom of sample disappeared rapidly because of height permeability. Trend of curve in this part is independent to pore water flow. Progressing of the test causes plugging water pass ways through the soil specimen, so relative pore pressure increases. Increasing of relative pore pressure is continued until a maximum value and then it is decreased by the end of tests. Actually,

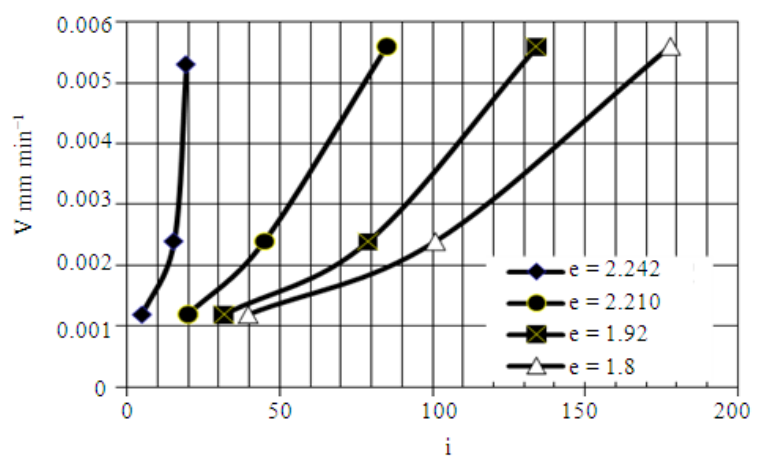

Fig. 6: Relationship between hydraulic gradient (i) and pore water velocity during CRS test on sample D

increase or decrease of relative pore pressure depends on flow rule. Flow resistance in Non-Darcy flow is greater than Darcy flow, hence flow rule in mid part seems Non-Darcy and in the last part it is Darcy. Indeed, higher resistance of pore water flow, NonDarcy flow, causes developing more excess pore pressure until changing flow rule to Darcy by increasing hydraulic gradients as well as reduction of flow resistance. Decreasing flow resistance causes decreasing of relative pore pressure because of rapid dissipation of excess pore pressure.

Relationship among hydraulic gradient and water flow velocity in soil often is used as exact method for defining flow rule as Darcy, if it is linear; and NonDarcy, if it is Non-linear. Throughout CRS consolidation test pore water drainage flow velocity is equal to strain rate of the test. Pore pressure at the upper side of specimens is atmospheric and at the bottom is measured by transducers so by given pore pressure at the both side of the specimen; hydraulic gradient at any time is determinable. Regarding to dynamic aspect of CRS consolidation, the void ratio as well as permeability is changing with time, hence just one point of hydraulic gradient (i) -Flow velocity (v) curve determinable for special void ratio or permeability; therefore distinguish of flow rule by the mentioned method explicitly is imposable. Owing to repetition of CRS tests with same condition on same specimens, there is possibility of getting gradient (i) -flow velocity (v) curves for the same void ratio of tested specimens. Consequently defining of exact flow rule will be feasible based on trend of curves such as linear or nonlinear. Figure 6 and 7 show the tests results that were conducted on Swedish soil samples. It is clear that the relation between flow velocity and hydraulic gradient is nonlinear and it means the flow rule during consolidation was Non-Darcy. Indeed, in a CRS test 
hydraulic gradient- flow velocity is a horizontal line when Y-axis assumed as pore flow velocity (Fig. 8, the dashed vector). However, if the test had been stopped in some times and had been conducted permeability tests for every stopping time, the hydraulic gradient-flow velocity curve would have been gotten as shown in Fig. 8. The Non-linearity of $\mathrm{V}-\mathrm{i}$ curves and also the thresholds of Non-Darcy and Darcy flow being greater by increasing consolidation as well as decreasing void ratio or soil permeability ${ }^{[6]}$, the same pattern is observing in Fig. 6 and 7.

Of course the thresholds values of Darcy flow rule in the studied cases seem greater than which is mentioned in literatures ${ }^{[7,10]}$. In the steady cases of water flow in prose media such as ordinary permeability which had studied by researchers ${ }^{[7,10]}$,

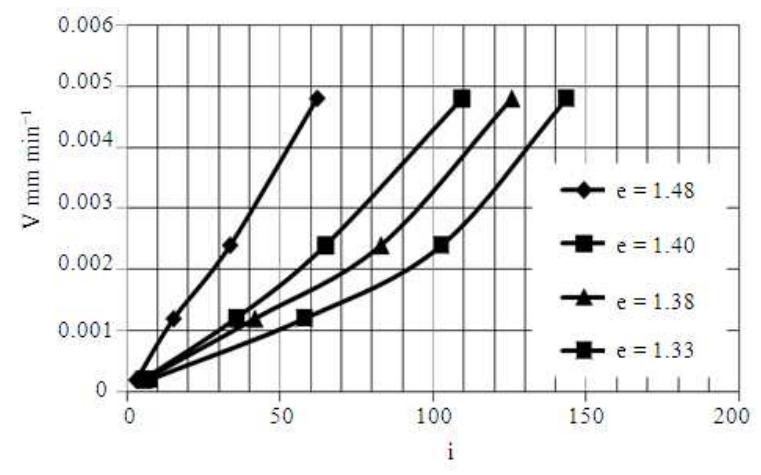

Fig. 7: Relationship between hydraulic gradient (i) and pore water velocity during CRS test on sample C

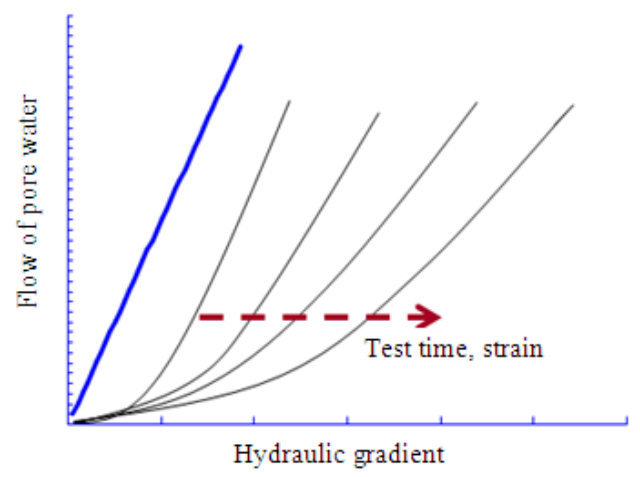

Fig. 8: Flow rule throughout CRS consolidation test. The dashed line in related to Darcy flow rule and the curves is non-Darcy curve which is shifted to the right while test and compression is continued the viscosity of water was the effective parameter to changing flow rule to Non-Darcy but in the CRS consolidation the rapid changing of flow pas way, because of compressing and changing of void ratio, is the main reason to existing Non-Darcy flow rule, the mentioned phenomenon is the one of main reasons of Non-Darcy flow ${ }^{[12]}$ Consequently, the flow rule in CRS consolidation seems Non-Darcy at the whole time of test or at least in half of it and Darcy flow rule is valid at the second half or at the last times of the test. As mentioned in introduction all equations that presented by researchers in the field of CRS consolidation is based on Darcy flow rule in which the governing flow rule is Non-Darcy often. Therefore to obtain reasonable results and also to determine realistic consolidation parameters considering of equations that relevant flow conditions have been included is necessary and essential. The proposed equation 10 can be useful in this regards.

The boundary of Darcy and non-Darcy: Researchers have showed water flow in clayey soils is Non-Darcy at lower hydraulic gradient which is changed to Darcy when hydraulic gradient being enough greater. During CRS consolidation applied stress increases every time therefore excess pore pressure at the base of specimen is developed more and more while the ratio of pore water pressure of bottom of specimen to applied stress has different trend. Based on applied strain rate the curve of relative pore pressure to stress-total stress may be divided to three parts as First, Mid and Last parts as explained above. As elucidated the mid section is bounded by a minimum and a maximum value of relative pore pressure. These two extremoms points are the points that the flow rule changes. Indeed the minimum points where relative pore water pressure is dropped down, is the starting of real one way consolidation. After starting one way consolidation the pattern of relative pore pressure will have two different trends. In the case of slow strain rate, if the tests be enough slow to dissipation excess pore water the trend of curve will remain almost stable until the end of the test (Fig. 4). Since, during consolidation void ratio reducing gradually, the permeability decreasing, therefore rate of dissipation of excess pore pressure may decreases and causes developing of excess pore pressure (Fig 9a and d). The increasing or developing of relative excess pore pressure is continued until a maximum value or a peak and then reduces slightly and then is remained steady. Although by progressive consolidation the void ratio as well as permeability is reduced, the relative pore pressure decrease after a peak. 


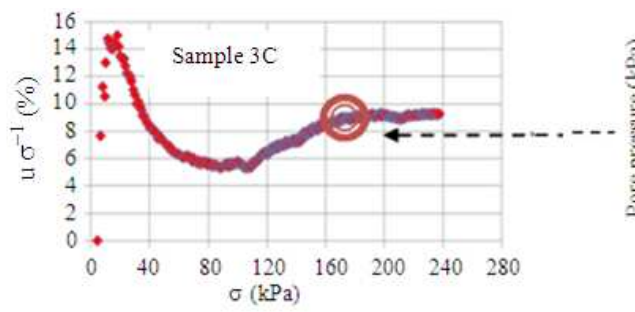

(a)

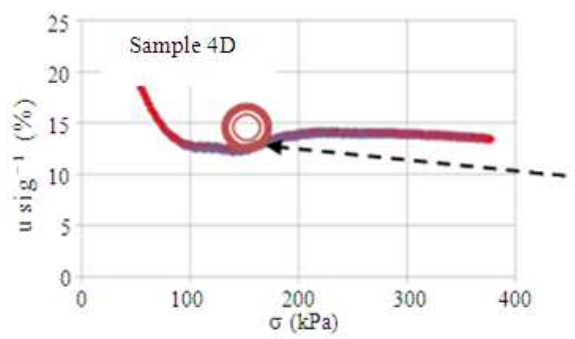

(c)

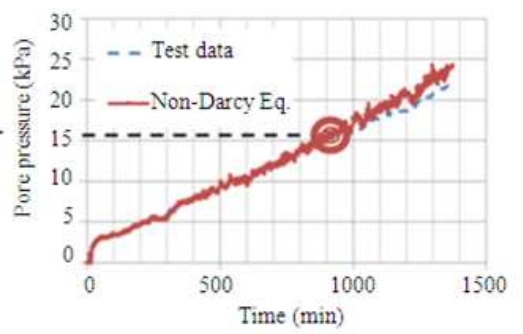

(b)

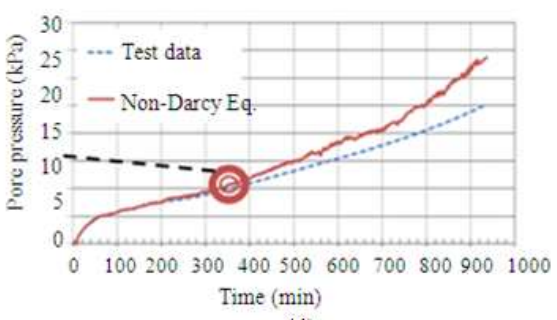

(d)

Fig. 9: Relationship between point of flow rule diversion from Darcy to Non-Darcy based on inclination changing of relative pore pressure-applied stress curve

Certainly feasibility in dissipation of excess pore water pressure is the reason of decreasing of excess pore pressure while permeability reducing because of compressing of specimen. In view of the fact that flow resistance in Darcy flow is less than Non-Darcy flow, the peak point on the curve of relative pore pressuretotal stress is boundary of Darcy and Non-Darcy flow. Comparison between related time of the mentioned peak pint with the diversion time of Eq. 11 results and test data confirmed mentioned hypothesis as peak point is the threshold of starting Darcy flow (Fig. 9).

Regarding to slow test that the relative pore pressure curve doesn't have Mid part, comparison test data with Eq. 11 has very good agreements so it seems that throughout slow CRS tests flow rule is Non-Darcy. This is may be an answer to why researchers didn't obtain correct results from slow CRS test and standards had to define a minimum bound for relative pore pressure $^{[4,2,16]}$, Since their used relation based on Darcy flow rule.

\section{DISCUSSION}

At present study the flow rule in CRS consolidation was investigated. The new presented equation confirmed by tests results and was used also for investigation of hydraulic condition of pore water flow. Based on review of author in literatures there wasn't any research in Non-Darcian flow related to CRS consolidation test. However, some researchers investigated a flow rule in IL consolidation tests ${ }^{[6-9]}$. As emphasized in this study, the flow rule in CRS consolidation mainly is Non-Darcy. The threshold of Darcy flow in the studied work is almost high hydraulic gradient in which it is in IL consolidation tests is a small value of hydraulic gradient ${ }^{[6-8,11]}$, of course very high value even as height as 900 reported as a threshold gradient for Darcy flow in clays ${ }^{[12]}$.

\section{CONCLUSION}

Based on the results of the conducted experiments and presented equation in the present study, the following conclusions are made:

- Comparison between presented pore pressure distribution equation results based on Non-Darcy flow rule and test data showed there is a very good agreement

- At the beginning of tests total stress is zero but there is a very low residual pore pressure because of saturated specimen and confined water between transducer and sample, therefore, relative pore pressure ( has a high value)

- Investigation on variation of excess pore pressure throughout CRS test showed that there is two main form of variation relative pore pressure (based on applied strain rate. In rapid tests the parameter has increasing and decreasing trend but in slow test it is almost constant 
- The shape of developing $\frac{u}{\sigma}-\sigma$ curves depends rigorously on hydraulic of drainage of pore water. In developed form this curve to be formed by three parts as First, Mid and last pasts. In the First and mid parts of the $\frac{\mathrm{u}}{\sigma}-\sigma$ curve, valid flow rule is Non-Darcy but in the last part the flow rule is Darcy

- In the some tests which $\frac{\mathrm{u}}{\sigma}-\sigma$ curves had three parts, there was a gap and difference between results of Eq. 11 and tests data. The initiation of differences was coincident on peak point of $\frac{u}{\sigma}-\sigma$ curve

- $\quad$ Regarding to obtain reasonable results and also to determine realistic consolidation parameters using equations that relevant flow conditions has been included them is essential and sufficient

\section{ACKNOWLEDGEMENT}

The researchers wish to express their deepest gratitude for research affairs of the University of Tehran and the deputy president of the UniversityCollege of Agriculture and Natural Resources for their full support of the project.

\section{REFERENCES}

1. Almeida, M.S.S., I.S. Martins and S.R.L. Carvalho, 1995. Constant rate of strain consolidation of Singapore marine clay. Geotechnique, 45: 333-336. http://cat.inist.fr/?aModele $=$ afficheN\&cpsidt $=3562$ 979

2. ASTM, 2002. Annual Book of ASTM Standards. American Society for Testing and Materials, Soil and Rock, ISBN: 0803132360, pp: 1170.

3. Gromen, C.T., T.C. Hopkins, R.C. Deen and V.P. Drenvich, 1978. Constant rate of strain and controlled gradient consolidation testing. Geotech. Test. J., 1: 3-15.

4. Hamilton, J.J. and C.B. Crawford, 1959. Improved determination preconsolidation pressure of a sensitive clay. ASTM. Special Tech. Publ., 254: 254-271. http://irc.nrc-cnrc.gc.ca/pubs/rp/rp115/

5. Hansbo, S., 1997. Aspects of vertical drain design: Darcian or non-Darcian flow. Geotechnique, 47: 983-992.

http://cat.inist.fr/?aModele $=$ afficheN\&cpsidt $=2085$ 028
6. Hansbo, S., 2001. Consolidation equation valid for both Darcian and non-Darcian flow. Geotechnique, 51: 51-54. http://cat.inist.fr/?aModele $=$ afficheN\&cpsidt $=9582$ 72

7. Hansbo, S., 2003. Deviation from Darcy's law observed in one-dimensional consolidation. Geotechnique, 53: 601-605. http://cat.inist.fr/?aModele $=$ afficheN\&cpsidt $=1501$ 7684

8. Indraratna, B. and I. Sathananthan, 2006. Planestrain lateral consolidation with non-Darcian flows. Can. Geotech. J., 43: 119-133. http://www.highbeam.com/doc/1G1148277443.html

9. Lee, K. and V. Choa, S.H. Lee and S.H. Quek, 1993. Constant rate of strain consolidation of Singapore marine clay. Geotechnique, 43: 471-488. http://direct.bl.uk/bld/PlaceOrder.do?UIN=027916 880\&ETOC $=\mathrm{EN} \&$ from $=$ searchengine

10. Malionowska, E., M. Sas and A. Szymanski, 2007. Nonlinear water flow characteristics describing organic soil consolidation. Elect. J. Polish Agric. Univ., $\quad 10$ : 41-41. http://www.ejpau.media.pl/volume10/issue4/art41.html

11. Mitchell, K.J. and K. Soga, 2005. Fundamental of Soil Behaviors. 3rd Edn., Wily and Sons, ISBN: 978-0-471-46302-3, pp: 592.

12. Schmermann, J.H., 1965. Discussion of interpretation of the consolidation test. J. Soil Mech. Found. Div. ASCE., 131-135.

13. Sheahan, T.C. and P.J. Watters, 1997. Experimental verification of CRS consolidation theory. J. Geotech. Geoenviron. Eng., 123: 430-437. http://cat.inist.fr/?aModele $=$ afficheN\&cpsidt $=2729$ 130

14. Smith, R.E. and H.E. Wahls, 1969. Consolidation under constant rate of strain. ACSE. J. Soil Mech. Found. Div., 95: 519-539.

15. Wissa, A.E.Z., J.T. Christian, E.H. Davis and S. Heiberg, 1971. Consolidation testing at constant rate of strain. J. Soil Mech. Found. Div., 97: 1393-1413. http://cedb.asce.org/cgi/WWWdisplay.cgi?7100953

16. Zen, K. and Y. Umehara, 1986. A new consolidation testing procedure and technique for very soft soils. ASTM., Special Tech. Pub., 892: 405-433. http://cat.inist.fr/?aModele $=$ afficheN\&cpsidt $=1625$ 0416 